${ }^{1,2}$ Kyoung Sook Jeong, ${ }^{3}$ Jin Zhou, ${ }^{3}$ Elizabeth Jacobs, 'Stephanie C Griffin, 'Sally Littau, ${ }^{4}$ John Gulotta, ${ }^{4}$ Paul Moore, ${ }^{1}$ Devi Dearmon-Moore, ${ }^{5}$ Wayne F Peate, ${ }^{1}$ Jeffery L Burgess. 'Dept of Community, Environment and Policy, University of Arizona, Tucson, Arizona, USA; ${ }^{2}$ Hallym University Sacred Heart Hospital, Anyang, South Korea; ${ }^{3}$ Department of Epidemiology and Biostatistics, University of Arizona, Tucson, Arizona. USA; ${ }^{4}$ Tucson Fire Department, Tucson, Arizona, USA; ${ }^{5}$ WellAmerica Inc., Tucson, Arizona, USA

\subsection{6/oemed-2018-ICOHabstracts.1144}

Introduction Firefighters are exposed to carcinogens and have elevated cancer rates. Cancer may be caused by activation of oncogenes or inhibition of tumour suppressor genes, such as through alterations in microRNA (miRNA) concentrations and DNA methylation. We hypothesised that occupational exposures in firefighters would lead to epigenetic changes associated with activation of cancer pathways and increased cancer risk. We designed this study to compare epigenetic changes in incumbent firefighters and new recruits.

Methods At the time of subject selection, the study population consisted of 119 incumbents and 70 recruits. From this group, 108 subjects were randomly selected for miRNA analysis and 96 for DNA methylation analysis, both evenly divided among incumbents and recruits. Only non-smoker male firefighters were included in the final comparison. MiRNAs and DNA methylation were measured with the nCounter Human v3 miRNA expression assay with over 828 miRNAs and the Illumina MethylationEPIC $850 \mathrm{k}$ chips, respectively.

Result After adjusting for age and BMI, miR-1260a, miR-1455 p, miR-181c-5p, miR-331-3 p, miR-361-5 p, and miR584$3 \mathrm{p}$ were significantly downregulated in incumbent firefighters. MiR-208b-5p, miR-30e-3p, and miR-486-3 p were significantly overexpressed in incumbents. Controlling the genomewide false discovery rate at 5\%,22 CpGs were annotated to promoter regions of a gene and were hypermethylated in the incumbents including YIPF6, HELB, SYT5 and DVL2.

Discussion MiR-181c-5p, miR-145-5 p, and miR-584-3 p are involved in tumour suppression. MiR-30e-3p is upregulated in skin cancer and is a poor prognostic factor in lung cancer. Co-amplification of the YIPF6 gene with the androgen receptor may stimulate prostate tumour progression. Aberrant activation of HELB reduces genomic stability, a hallmark of cancer. SYT may have a novel function in breast cancer. DVL2 is a part of the Wnt signalling pathway involved in multiple cancers. These epigenetic biomarkers of carcinogenic exposure in firefighters should be further evaluated in larger studies.

\section{THE DECREASE OF BIOLOGICAL BLOOD LEAD LEVELS AT A LEAD NITRATE PLANT IN SOUTH AFRICA}

Susanne Martinuzzi*. SHE Consultant, Aerocell (Pty) Ltd, Springs, South Africa

\subsection{6/oemed-2018-ICOHabstracts. 1145}

Introduction Following a significant increase in production at a Lead Nitrate plant in South Africa, the blood lead levels in their employees also increased. This was concerning as the average blood Lead results in 2015 increased to $43 \mathrm{ug} / \mathrm{dl}$, well above the legal South African National limit of $<20 \mathrm{ug} / \mathrm{dl}$. This prompted the need to introduce more stringent controls/ interventions in order to decrease the average blood Lead levels and avoid adverse health effects to the workers.
Methods The controls/interventions used, comprised the following;

- a retrospective analysis of all historical biological monitoring results with direct comparisons to the man-job specifications, as well as the occupational hygiene monitoring results of airborne pollutants;

- an intensive Lead study, which included a visit to a nearby Lead refining facility to obtain comparative data;

- the demarcation and separation of work zones including changing and dining facilities;

- conducting of medical examinations, to include Lead effect monitoring;

- a review of personal protective equipment (PPE) and implementation of controls to ensure correct use thereof;

- introduction of a comprehensive Lead-health training programme; and

- introduction of a three-monthly biological blood Lead monitoring and counselling programme.

Results As a consequence of the above controls/interventions, the average blood Lead level decreased from $43 \mathrm{ug} / \mathrm{dl}$ in 2015 , to $23 \mathrm{ug} / \mathrm{dl}$ for the half year average of 2017, representing a $45 \%$ decrease over a period of 18 months. Some employees achieved significant decreases in lead levels, from well above $30 \mathrm{ug} / \mathrm{dl}$ to well below $20 \mathrm{ug} / \mathrm{dl}$.

Discussion An increased understanding and awareness of the hazards of Lead, both by the employer and employees, resulted in a significant decrease in the average blood Lead burden of the workforce. The continuous application of control/interventions in the workplace should lead to further decrease in the average blood Lead levels well below the South African legal limit.

\section{OCCUPATIONAL DIOXIN EXPOSURE OF WORKERS IN MUNICIPAL WASTE INCINERATORS}

1,2M De Meester*, 1,2P Kiss, '2 Braeckman. 'Securex Occupational Health Service, Ghent, Belgium; ${ }^{2}$ Department of Public Health, Ghent University, Ghent, Belgium

\subsection{6/oemed-2018-ICOHabstracts.1146}

Introduction In combustion ashes and dust in the machine hall of two municipal waste incinerators in Flanders, dioxin-like substances were found. The aim of this study was to explore if exposure to these ashes and dust induced an increased uptake of dioxin-like substances.

Methods 50 subjects working in two municipal waste incinerators participated, comprising 32 maintenance workers exposed to dust and ashes, 7 garage workers and 11 administrative workers. The exposed workers were divided according to seniority ( $\leq 10$ years. and $>10$ years.). Serum dioxin-like activity was assessed by chemical-activated luciferase gene expression (CALUX) assay. Following non-occupational factors were assessed by questionnaire: BMI, smoking, living near a road with heavy traffic and nutrition intake.

As dioxins accumulate in the body, higher serum dioxin levels could be expected in the exposed maintenance workers. Therefore, the serum dioxin levels of the maintenance workers group were compared with those of the other groups. Additionally, maintenance workers with $\geq 10$ years. seniority were compared with workers with $<10$ years. seniority. Mann-Whitney $\mathrm{U}$ test and Kruskal-Wallis were used where appropriate. 